\title{
The new Neurology
}

\section{Designed for reader engagement and increased depth of research reporting}

Patricia K. Baskin, MS, and Robert A. Gross, MD, PhD

Neurology ${ }^{\oplus}$ 2018;90:12-13. doi:10.1212/WNL.0000000000004759

You are holding in your hands the redesigned Neurology $y^{\circledR}$, a 2018 pilot project in the making for the last 1.5 years and informed by extensive research regarding what readers want in a print reading experience and what researchers want online. The new design reflects changes in science and technology that have affected all neurologists' lives; the result is increasing difficulty in finding time to stay at the top of their areas of expertise and keeping abreast of changes in other subspecialties. The new print journal is the reader's journal—intended for reading cover to cover with content presented in a way that is a meaningful experience both to the general neurologist and subspecialist researcher. The online version remains the canonical record of the journal.

\section{The short-format article and the new print design}

The foremost change in the print journal is that all the research articles are presented in a 1-page format. These short articles will make it easier to stay up to date with the latest research by placing the findings in context of current knowledge in the area, conveying the limitations and strengths of the study and the next steps for expanding the research, and facilitating the use of the results in clinical practice.

\section{Full-length online expanded article format for research journals and the new online design}

Authors submitting research papers are now allotted up to 4,500 words (an increase from 3,000), with reviews lengthening to 5,000 words or less, along with more figures and tables. The entire article will be published in the expanded online version of the journal for anyone who wishes to read all the details of the study. Our new online redesign provides increased functionality for search and discovery across the Neurology family of journals. The online journal will have recommendations for further reading, links for commenting on the article, links to most read and most cited articles, new editor summaries of issue contents, play-in-place video supplements, and an intriguing image of the week. As we enter phase II of our redesigns, we will be incorporating new features and functionality to make the online journal even more useful.

\section{Evolution of the print journal}

As the new year progresses, the print version of the journal will include more features that make visible many facets of Neurology you may have been missing: sample pages from the onlineonly Resident \& Fellow section, abstracts from the online-only spin-off journals Neurology ${ }^{\circledR}$ Neuroimmunology \& Neuroinflammation and Neurology ${ }^{\circledR}$ Genetics, and also from our journal especially produced for the practicing neurologist, Neurology ${ }^{\circledR}$ Clinical Practice. We will give you a heads-up about what is new and interesting in Neurology-describing the latest podcasts, articles in the news, articles that have been highly read or cited, and some tips or links to content useful for authors.

We will also bring you more news from our special interest sites, Innovations in Care Delivery and Without Borders, in the print version. The editors will share some of the recent articles displayed on the site, along with short commentary, or summarize interesting recent blog postings.

In keeping with the spirit of providing what readers have requested, these features and content will be digestible in short bites that expose our readers to the multiple forms in which the journal
Correspondence

P.K. Baskin

pbaskin@neurology.org

From the American Academy of Neurology (P.K.B.), Minneapolis, MN; and Strong Epilepsy Center and University of Rochester Medical Center (R.A.G.), NY.

Go to Neurology.org/N for full disclosures. Funding information and disclosures deemed relevant by the authors, if any, are provided at the end of the editorial. 
provides information. We will continue throughout the year to monitor the effectiveness of our new formats. We welcome your thoughts and comments. Write to us at journal@neurology.org.

Happy reading!

\section{Disclosure}

Patricia K. Baskin is Executive Editor of the Neurology journals and employed by the American Academy of Neurology. P.K. Baskin has consulted with no stipend or reimbursements for the Medical Publishing Insights and Practices initiative. She has served as Editor-in-Chief of Science Editor and is Immediate Past-President of the Council of Science Editors. Robert A. Gross, $\mathrm{MD}, \mathrm{PhD}, \mathrm{FAAN}$, is supported for educational endeavors by the University of Rochester Medical Center's Clinical and Translational Science Award from the NIH. Since his appointment as Editor-in-Chief in 2009, Dr. Gross ceased participation in industry-sponsored clinical trials and speakers' bureaus. He receives an honorarium from AAN as Editor-inChief of Neurology. Go to Neurology.org/N for full disclosures. 


\section{Neurology}

\section{The new Neurology: Designed for reader engagement and increased depth of research reporting}

Patricia K. Baskin and Robert A. Gross

Neurology 2018;90;12-13

DOI 10.1212/WNL.0000000000004759

This information is current as of December 28, 2017

\section{Updated Information \&} Services

Permissions \& Licensing

\section{Reprints}

including high resolution figures, can be found at: http://n.neurology.org/content/90/1/12.full

Information about reproducing this article in parts (figures,tables) or in its entirety can be found online at:

http://www.neurology.org/about/about_the_journal\#permissions

Information about ordering reprints can be found online:

http://n.neurology.org/subscribers/advertise

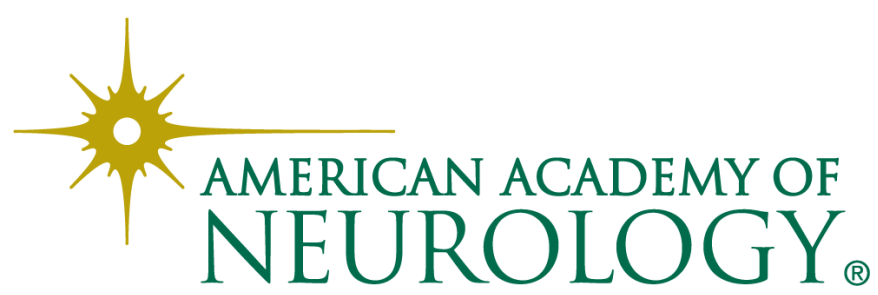

